\title{
Drugs Hypersensitivity Reaction in Patient with Human Immunodeficiency Virus (HIV) Infection
}

\author{
Rahmawati Minhajat ${ }^{1,2^{*}}$, Irawaty Djaharuddin ${ }^{3}$, Risna Halim ${ }^{4}$, Andi Fachruddin Benyamin ${ }^{5}$ and Syakib Bakri ${ }^{6}$ \\ ${ }^{1}$ Internal Medicine Department, Hematology and Medical Oncology Division, Medical Faculty Hasanuddin University, Makassar, Indonesia \\ ${ }^{2}$ Histology Department, Medical Faculty Hasanuddin University, Makassar, Indonesia \\ 3 Internal Medicine Department, Pulmonology Division, Medical Faculty, Hasanuddin University, Makassar, Indonesia \\ ${ }^{4}$ Internal Medicine Department, Tropic and Infection Division, Medical Faculty, Hasanuddin University, Makassar, Indonesia \\ 5Internal Medicine Department, Hematology and Medical Oncology Division, Medical Faculty, Hasanuddin University, Makassar, Indonesia \\ ${ }^{6}$ Internal Medicine Department, Nephrology and Hypertension Division, Medical Faculty, Hasanuddin University, Makassar, Indonesia
}

*Corresponding author: Rahmawati Minhajat, Internal Medicine Department, Hematology and Medical Oncology Division, Medical Faculty Hasanuddin University, Makassar, Indonesia, E-mail: rahmawatiminhajat@med.unhas.ac.id

Received date: March 14, 2017; Accepted date: March 22, 2017; Published date: March 31, 2017

Copyright: $\odot 2017$ Minhajat R, et al. This is an open-access article distributed under the terms of the Creative Commons Attribution License, which permits unrestricted use, distribution, and reproduction in any medium, provided the original author and source are credited.

\begin{abstract}
A case of male, 34 years old with a diagnosis of immunodeficiency syndrome resulting from HIV infection with suspected pneumonia in the differential diagnosis of pulmonary tuberculosis relapse, in the course of the disease, patients experienced hypersensitivity reactions to some antibiotics and antituberculosis drugs. Hypersensitivity reactions were exaggerated by immune response to an allergen in a normal immune system. In this case, we found the drug hypersensitivity reactions in patients with immunodeficiency. Until now, the exact underlying mechanism is not fully known but may be due to multifactorial and the dysregulation of the immune system due to HIV infection.
\end{abstract}

Keywords: AIDS; Immunodeficiency; Hypersensitivity

\section{Introduction}

Acquired Immunodeficiency Syndrome (AIDS) is a collection of symptoms caused by Human Immunodeficiency Virus (HIV) infection, an RNA virus including Retrovirus from the lentivirus family, which attacks the immune system $[1,2]$.

The main target of HIV infection is the CD4+ lymphocytes ( $\mathrm{T}$ helper/Th) which play a central role in the immune system. In the early course of the disease, the immune system can control the HIV infection, but with the course of the disease, HIV will further cause a decrease number of CD4+ lymphocytes, disruption of homeostasis and function of other cells in the immune system. This situation will further lead to various symptoms with a wide clinical spectrum as the result of a disturbance in the function of cellular and humoral immunity. These viruses cause disease through several mechanisms including immune deficiency that causes opportunistic infections, autoimmune reactions and hypersensitivity reactions as well as tendency of malignancy $[1,2]$.

Hypersensitivity reactions are excessive immune response to an allergen in a normal immune system. Drug hypersensitivity is an excessive immune response to the drug substance or its metabolites through immunological reactions that occur during or after the use of drugs in which this mechanism may be mediated by immunoglobulin or T lymphocytes. Hypersensitivity reactions according to Gell and Coombs are classified into four types: type I reaction is immediate hypersensitivity played by IgE, the type II reaction is a cytotoxic reaction played by $\operatorname{IgM} / \mathrm{IgG}$, type III reaction or immune complex reaction played by IgM/IgG, and type IV reactions are delayed type hypersensitivity that is not played by antibodies but by $\mathrm{T}$ lymphocytes [3].

Drug hypersensitivity reaction in HIV infection often occurs. In fact, it is reported to occur 100 times more frequently than non-HIV patients. Drug hypersensitivity reactions in HIV-infected patients are clinically similar to drug hypersensitivity reactions in non HIVinfected [4]. Although drug hypersensitivity reactions in patients with HIV infection often occurs but the case is very rarely reported.

We report one case, male 34 years with immunodeficiency syndrome due to HIV infection in the course of his illness he experienced a hypersensitivity reaction to some antibiotics and antituberculosis drugs.

\section{Case Report}

A male patient, 34 years old, entered hospital with a chief complaint of shortness of breath experienced since one week before hospitalization. Shortness of breath was felt constantly, not influenced by the activity and positional change. Since a week ago, patient experienced productive cough, with white mucous, no blood, left chest pain is felt especially when coughing. Fever experienced since one week, especially at night, no chills, no seizures and no headache. No nausea and vomiting, loss of appetite three days before entering the hospital. Patients gained weight in the last six months but previously experienced a weight loss of about $5-10 \mathrm{~kg}$ in five years. Normal urination and defecation.

No history of asthma and food or medication allergies, no history of recurrent diarrhea, no history of blood transfusion, there is a history of smoking since high school and drug abuse, no history of free sex. Other data regarding the history of previous illness was ever treated with typhoid fever in 1998, 2001 and 2004. In 2004 history of Morbili, 
2005 hospitalized with heart valve disorder, and 2009 patients had recurrent stomatitis accompanied by infection of left and dextra inguinal. Patient was given Ciprofoxacin but allergic skin symptoms appeared after a few minutes taking the drug. Since January 2010 he was diagnosed with lung tuberculosis. Patient was given oral antituberculosis drugs, 4 Fixed Dose Combination (4FDC) four times a day. Allergy symptoms such as skin rash appeared at the whole body accompanied by itching and shortness of breath which occured after approximately one week taking the 4FDC medication. FDC then replaced with separate medicine (Rifampicin/INH/Pyrazinamide/ Ethambutol). About a week later the same allergy symptoms appeared, and then the patient was declared allergic to Rifampicin and Pyrazinamide.

The physical examination found, the impression was seriously ill, well-nourished with body mass index (BMI) of $23.3 \mathrm{~kg} / \mathrm{m}^{2}$, compos mentis, blood pressure $120 / 80 \mathrm{mmHg}$, respiratory 30 times per minute thoracoabdominal, $38,20^{\circ} \mathrm{C}$ axillary temperature, pulse 92 times/ minute. Examination of the oral cavity found oral candidiasis. Bronkovesikuler breath sounds on thoracic auscultation, additional sound was rales at the apex of the left lung, no wheezing.

Based on the history and physical examination, working diagnosis was suspected pneumonia with differential diagnosis pulmonary TB relaps and suspected immunodeficiency syndrome. Initial therapy was given high-protein, high-calorie diet, oxygen, isotonic infusion fluid and paracetamol. Until the third day of treatment, patients often experienced shortness of breath, fever $\left(37.80^{\circ} \mathrm{C}\right.$ to $\left.39.50^{\circ} \mathrm{C}\right)$, coughing with sputum. Oral candidiasis, bronkovesikuler respiratory sounds, rales at the apex of the left lung. Laboratory results; leukocytes 9,800/uL, hemoglobin; $10.3 \mathrm{~g} / \mathrm{dl}$, the red blood cells: $5.42 \times 106 / \mathrm{uL}$, hematocrit; 33.8\%, platelets; 274,000 /uL, monocytes; 9\%, segment; $82 \%$, lymphocytes; $9 \%$, eosinophil $8 \%$, erythrocyte sedimentation rate; $74 \mathrm{~mm} 1^{\text {st }} \mathrm{h}$ and $92 \mathrm{~mm}$ at 2 nd hour, renal function within normal limits and chest X-ray impression: bilateral bronchopneumonia. Additional therapy was given Ceftriaxone injection $1 \mathrm{~g} / 12 \mathrm{~h}$, skin test before ceftriaxon injection found positive allergic reactions such as erythema and edema locally. Ceftriaxone then replaced by $200 \mathrm{mg}$ Ofloxacin twice daily. Laboratory results of HIV rapid test is reactive (positive), CD4 laboratory results; the absolute value was 18 cells/pl (Normal range 410-1590 cells/pl) and the percentage was 2\% (Normal range 31-60), the T-helper lymphocytes count was very less. Patient confirmed positive HIV. Added ARV therapy (Lamivudine, Zidovudine and efavirenz) twice daily, Ceftazidine $1 \mathrm{~g} / 12 \mathrm{~h} / \mathrm{IV}$, but the results show positive skin test allergy (local erythema and edema). Ceftazidine replaced with Cefotaxime $1 \mathrm{~g}$ twice daily intravenous. Other drugs are co-trimoxazole, Bromhexine HCL and Fluconazole (Table 1).

\begin{tabular}{|l|l|l|l|l|}
\hline Time & September 2009 & January 2010 & July 2010 & July 2010 \\
\hline Drug name & Ciprofloxacin & $\begin{array}{l}\text { Rifampicin } \\
\text { Pyrazinamide }\end{array}$ & Ceftriaxon & Ceftazidine \\
\hline $\begin{array}{l}\text { Time of reaction after taking the } \\
\text { drug }\end{array}$ & A few minutes & A week & 5 minutes & 5 minutes \\
\hline Symptoms & $\begin{array}{l}\text { Red spots on the skin of the whole } \\
\text { body accompanied by intense } \\
\text { itching and nausea }\end{array}$ & $\begin{array}{l}\text { Red spots on the skin the whole } \\
\text { body accompanied by intense } \\
\text { itching and shortness of breath }\end{array}$ & $\begin{array}{l}\text { Red spots and edema when } \\
\text { skin tests }\end{array}$ & $\begin{array}{l}\text { Red spots and edema when } \\
\text { skin tests }\end{array}$ \\
\hline
\end{tabular}

Table 1: Summary of drugs hypersensitivity reaction history.

On the $15^{\text {th }}$ day of treatment, the patient was allowed to go home and outpatient care. At that time the patient's condition is good, no fever, no shortness of breath, a temperature of $36^{\circ} \mathrm{C}$, respiratory 16 times per minute, no oral candidiasis, respiratory sound bronchovesicular with rales at the apex of the left lung.

\section{Discussion}

We reported a case, male 34 years with immunodeficiency syndrome resulting from HIV infection with suspected pneumonia, pulmonary TB relapse, and in the course of his illness, patients experienced hypersensitivity reactions to some antibiotics and antituberculosis drugs. Further discussion on this case focused on the drug hypersensitivity reactions in immunodeficiency due to HIV infection.

Patient in this case did not have a history of allergic diseases or allergies to drugs and food. A tendency to experience allergic reactions begins to occur after the appearance of symptoms of immunodeficiency disease. Reported that a hypersensitivity reaction to trimethoprim-sulfametoksazole occurs $60 \%$ in HIV-positive patients and only $5 \%$ in immunocompetent or immunodeficient not due to HIV infection. Giving antituberculosis isoniazid (INH), pyrazinamide
(PZA) and rifampicin in HIV-infected patients will be at risk of drug hypersensitivity 20 times more often than those who not HIV-infected [5]. The drugs often reported allergic reactions in patients who are HIV positive is trimethoprim-sulfamethoxazole, penicillin group, antituberculosis, antiretroviral, non-steroidal anti-inflammatory drugs (NSAIDs) and anticonvulsants [6]. The reason underlying the increase in drug hypersensitivity reactions in people infected with HIV have not clearly known, but the dysregulation of the immune system on $\mathrm{T}$ and B lymphocytes is likely play a role and some multifactorial including changes in drug metabolism, oxidative stress, cytokine profile, hyperactivation of the immune system and genetic factors are suspected play a role for this mechanism. HIV itself can be a dangerous signal that tends to cause an immune response than the immune tolerance [5,7].

The pathogenesis of hypersensitivity reactions in HIV infection is not clearly known, considered through an allergic reaction (immune mediated) or because of unknown causes toxic. However, this hypersensitivity reaction cannot be put into one of the four types of hypersensitivity reactions by Gell and Coombs classification. This is indeed very contradictory that hypersensitivity reaction occurs in people who 'energy' against some other stimulants [8]. 
Some conditions are thought to play a role [1,9], disregulations on the immune system: reaction to amoxicillin, trimethoprimsulfametokzasol and OAT medicine often occurs in low CD4 levels $(20-<200 / \mathrm{uL})$. Histopathologic examination showed similar abnormalities, independent to the drug precipitating, estimated as the general nature pathogenesis [2]. Co-infection with other viruses: such as Epstein-Barr virus (EBV), cytomegalovirus (CMV) and some other respiratory viruses reported to be associated with the occurrence of skin rash due to Ampicillin. Not found the incidence of skin rash when the acute phase of infection by these viruses has passed [3]. The dose and duration of using drug also play a role: It's found that hypersensitivity reaction often occur for the high-dose trimethoprimsulfametokzasol when compared with low doses as a prophylactic. The longer the medicine consumed, the higher possibility of a hypersensitivity reaction [4]. Other factors ecg immunoglobulins that are specific to a particular drug and drug structure and its metabolism in the body.

CD4+ lymphocytes is a central regulator of the immune system that these cells have two types of T helper-1 (Th-1) and -2 (Th-2) which are differentiated by cytokines released. Th-1 cells produce interferon gamma (INF-y) and interleukin (IL)-2 which is an important mediator of the cellular immune response, while $\mathrm{Th}-2$ produces IL-4, IL-5, IL-6 and IL-10 which is an important mediator for the humoral immune respon that help B lymphocytes produce antibodies [10]. HIV infection not only causes immunodeficiency, but also lead to dysregulation of the immune system. It plays an important role in the progression of the HIV disease [11]. Once infected by HIV, changes in cytokine profiles appears as it found an increase in production of IL-4 which is always accompanied by increased production of IL-5 and decreased production of INF-y [10]. Clerici et al. reported that in the early phase of HIV infection, the cytokines produced by Th-1 and Th- 2 still in a normal balance, but later, the cytokines produced by Th-2 (IL-4) increase while cytokine produced by Th-1 (IL-2) decrease. It supports the shift from Th-1 to Th-2 in the early phase of HIV infection [12]. Clinical findings that support an increase in the production of Th-2 cytokine is the allergic manifestation and increase levels of IgE in patients infected with HIV, in which the increase serum levels of IgE significantly associated with a reduction in CD4+ cells count (less than $200 / \mathrm{mm}^{2}$ ) [13-15]. In the further clinical course, the progressive decline in the production of IL-2 and IL-4 cytokines occur. In the humoral immune system, HIV itself causes the stimulation of $\mathrm{B}$ lymphocytes polyclonally and unspecificaly which cause a problem because of an unappropriate immune response [12].

The results of in vitro studies demonstrate that HIV-infected cells may be more susceptible to damage and cell death directly due to the reaction of drug metabolites, further damage or cell death is then interpreted as a "danger signal" and stimulate the T lymphocytes to initiate a series of immune responses and the release of cytokines which manifests as a drugs hypersensitivity reaction [16]. Glutathione deficiency in HIV infection is considered as another mechanism that may be the cause. Other studies demonstrate that HIV replication is stimulated by Tat protein, which is the Tat protein expression associated with increased oxidative stress, decreased glutathione biosynthesis and cellular concentration. Glutathione seems to play a role in protection of cells from a toxic metabolite substance $[5,17]$.

Some types of viral infection is associated with the occurrence of an allergic reaction to medicine. The virus include; human herpes virus 6 (HHV-6), Epstein-Barr virus (EBV) and paramixovirus. Co-infection with some viruses common in HIV positive patients. Virus can interact with the immune system through several points; during drug metabolism, during the presentation of medicine/drug metabolites by dendritic cells as antigen presenting cells (APC) to lymphocytes and when cytokine and kemokin production [18-20].

In 1992, from Zimbabwe reported that the anti-tuberculosis drug reactions more frequently in HIV-positive patients (98 of 363 patients) than patients who were not infected with HIV (64 of 543). Most frequent clinical manifestations of hypersensitivity reactions due to OAT medicine in HIV-positive patients are skin hypersensitive (64\%). This reaction arises almost entirely within the first 8 weeks giving OAT [21,22]. In this case, the patient has an allergy when taking OAT 4FDC, reddish spots appeared at the entire body accompanied by itching and shortness of breath that comes after a week of taking the medication. After administration of antituberculosis medicine separately, the patient then known allergic to Rifampicin and Pyrazinamide. In the combination therapy, it is difficult to determine which drug caused the reaction but Rifampicin is reported as the most frequent cause of reaction [23]. These patients also have allergic reactions to quinolones class. Anaphylactic reaction to ciprofloxacin were reported more frequently found in HIV-positive patients and often fatal $[23,24]$.

Action taken in the event of drug hypersensitivity reactions in patients with immunodeficiency is to stop or avoid medications shown to cause hypersensitivity reactions and replace with other drugs with the same therapeutic purposes. Desensitization or the role of using corticosteroids as immunosuppresant is fully unknown. Treatment aimed essentially for the underlying disease in which hypersensitivity reactions will disappear along with the improvement of the patient's immune system [2].

\section{Summary}

We reported a case, male 34 years with immunodeficiency syndrome resulting from HIV infection with suspected pneumonia, pulmonary $\mathrm{TB}$ relapse, and in the course of his illness, patients experienced hypersensitivity reactions to some antibiotics and OAT.

Patient in this case did not have a history of allergic diseases or allergies to drugs and food. A tendency to experience allergic reactions to some medicines begin occurs after the appearance of immunodeficiency disease symptoms. The clinical symptoms of allergy reaction were reddish spots at entire body accompanied by itching and shortness of breath.

Drugs hypersensitivity reactions are more common in HIV-infected patients. Until now, the exact mechanism underlying this reaction is not fully known but may be due to multifactorial and the dysregulation of the immune system by HIV infection. However, at immunodeficiency drugs hypersensitivity cannot be entered in the one of four types of hypersensitivity reactions by Gell and Coombs classification.

\section{References}

1. French RF, Stewart GJ, Penny R, Levy JA (1997) How HIV produces immune deficiency: Managing HIV. Med J Aust 164: 166-171.

2. Carr A, Cooper DA, Penny R (1991) Allergic manifestations of human immunodeficiency virus (HIV) infection. J Clin Immunol 11: 55-64.

3. Rajan TV (2003) The Gell-Coombs classification of hypersensitivity reactions: a re-interpretation. Trends Immunol 24: 376-379. 
Citation: Minhajat R, Djaharuddin I, Halim R, Benyamin AF, Bakri S (2017) Drugs Hypersensitivity Reaction in Patient with Human Immunodeficiency Virus (HIV) Infection. J Allergy Ther 8: 252. doi:10.4172/2155-6121.1000252

Page 4 of 4

4. Coopman SA, Johnson RA, Platt R (1993) Cutaneous disease and drug reactions in HIV infection. N Engl J Med 23: 1670-1674.

5. Phillips E, Mallal S (2007) Drug hypersensitivity in HIV. Curr Opin Allergy Clin Immunol 7: 324-330.

6. Dlova CN, Mosam A (2006) Drug reactions and the skin in HIV/AIDS South Afr J HIV Med 7: 18-22.

7. Chaponda M, Pirmohamed M (2011) Pirmohamed M Hypersensitivity reactions to HIV therapy. Br J Clin Pharmacol 71: 659-671.

8. Carr A, Garsia R (1996) How HIV leads to hypersensitivity reactions: Managing HIV. Med J Aust 164: 227-229.

9. Merati TP, Djauzi S (2011) Respon imun infeksi HIV. Jakarta Allergy and Immunology Network.

10. Meyaard L, Otto SA, Keet IP (1994) Changes in cytokine secretion patterns of $\mathrm{CD} 4+\mathrm{T}$-cell clones in human immunodeficiency virus infection. Blood 84: 4262-4268.

11. Calabrese LH (1988) Autoimmune manifestations of human immunodeficiency virus (HIV) infection. Clin Lab Med 8: 269-279.

12. Clerici M, Hakim FT, Venzon DJ, Blatt S, Hendrix CW, et al. (1993) Changes in interleukin-2 and interleukin-4 production in asymptomatic human immunodeficiency virus-seropositive individuals. J Clin Invest 91 759-765.

13. Small CB, Kaufman A, Armenaka M, Rosenstreich DL (1993) Sinusitis and atopy in human immunodeficiency virus infection. J Infect Dis 167: 283-290.

14. Sample S, Chernoff DN, Lenahan GA, Serwonska MH, Rangi S, et al. (1990) Elevated serum concentrations of IgE antibodies to environmental antigens in HIV-seropositive male homosexuals. J Allergy Clin Immunol 86: $876-880$.
15. Wright DN, Nelson RP Jr, Ledford DK, Fernandez-Caldas E, Trudeau WL, et al. (1990) Serum IgE and human immunodeficiency virus (HIV) infection. J Allergy Clin Immunol 85: 445-452.

16. Naisbitt DJ, Vilar FJ, Stalford AC, Wilkins EG, Pirmohamed M, et al. (2000) Plasma cysteine deficiency and decreased reduction of nitrososulfamethoxazole with HIV infection. AIDS Res Hum Retroviruses 16: 1929-1938.

17. Walmsley SL, Winn LM, Harrison ML, Uetrecht JP, Wells PG, et al. (1997) Oxidative stress and thio depletion in plasma and peripheral blood lymphocytes from HIV-infected patients: toxicological and pathological implications. AIDS 11: 1689-1697.

18. Torres MJ, Mayorga C, Blanca M (2009) Nonimmediate allergic reactions induced by drugs: pathogenesis and diagnostic tests. J Investig Allergol Clin Immuno 19: 80-90.

19. Merk HF, Niederau D, Hertl M, Jugert F (1991) Drug metabolism and drug allergy. New Trends in Allergy III pp: 269-280.

20. Levy M (1984) The combined effect of virus and drugs in drug-induced diseases. Med Hypotheses 14: 293-296.

21. Empson M, Bishop AG, Nightingale B, Garsia R (1999) Atopy, anergic status, and cytokineexpression in HIV-infected subjects. J Allergy Clin Immunol 103: 833-842.

22. Pozniak AL, MacLeod GA, Mahari M, Legg W, Weinberg J, et al. (1992) The influence of HIV status on single and multiple drug reactions to antituberculous therapy in Africa. AIDS 6: 809-814.

23. Bates CM (1996) HIV medicine: drug side effects and interactions. Postgrad Med 72: 30-33.

24. Peters B, Pinching AJ (1989) Fatal anaphylaxis associated with ciprofloxacin in a patient with AIDS related complex. BMJ 298: 605 . 